\title{
FRATERNIDADE, BEM COMUM E DIREITOS HUMANOS: REFLEXÕES IMPOSTAS PELA PANDEMIA
}

\author{
Carolina Simões Correia ${ }^{1}$
}

Luis Fernando Barzotto ${ }^{2}$

DOI: https://doi.org/10.47306/978-65-88213-03-2.207-221

\begin{abstract}
Sumário: 1 Introdução; 2 A natureza dos direitos humanos; 2.1 Os bens e os direitos humanos; 2.2 Diretos, deveres humanos e bem comum. O arquétipo da fraternidade; 3. A Declaração Universal dos Direitos Humanos (1948). Universalidade e Interdependência; 3.1 Os bens protegidos pela Declaração Universal dos Direitos Humanos (1948); 4 A racionalidade e a moralidade exigidas nas decisões concernentes à pandemia; 5 Direitos e Deveres. Uma ética universalizável da fraternidade; 6. Conclusão; Referências.
\end{abstract}

\section{Introdução}

Toda concepção dos direitos humanos é tributária de uma antropologia que determine quais os bens necessários para o florescimento humano. Ainda, ao considerarmos os direitos humanos como aspectos do bem comum, estarão na dependência de um conjunto de fatores que deem razões para a colaboração e o estabelecimento de vínculos entre os seres humanos para que estejam disponíveis à recíprocas concessões de direitos. Ou seja, se é inviável garantir o gozo de todos os direitos humanos para todos, a todo tempo, e até mesmo para uma maioria, uma compreensão correta do bem comum depende não tanto das condições materiais de gozo dos direitos, mas do tipo de relacionamento que se estabelece entre as pessoas, das condições de diálogo existentes para o estabelecimento de objetivos comuns e concessões recíprocas. Emerge então a categoria da fraternidade como 'caso central' de uma comunidade que é capaz de tomar decisões concernentes aos conflitos entre direitos preservando direitos primários, considerados absolutos, e harmonizando os interesses subjacentes a direitos secundários, cuja forma de realização pode ser relativizada.

Nesse artigo realizamos uma análise do atual discurso sobre os direitos humanos, partindo de duas suposições fundamentais: a) a Declaração Universal dos Direitos Humanos

\footnotetext{
1 Mestranda do Programa de Pós-Graduação em Direito pela Universidade Federal do Rio Grande do Sul (UFRGS). Endereço eletrônico carolinacorreia@tjrs.jus.br.

2 Professor Titular de Filosofia do Direito da Universidade Federal do Rio Grande do Sul (UFRGS). Endereço eletrônico luis.barzotto@ufrgs.br.
} 
(1948) tem uma visão específica de ser humano e propõe uma ética consequente à essa visão, a ética da fraternidade e; b) com base nessa ética, quando identificamos os bens necessários ao pleno desenvolvimento dos seres humanos, é possível estabelecer uma espécie de hierarquia entre os direitos tutelados na $D U D H$ (1948) que, ao preservar os bens mais caros à dignidade humana em cada caso concreto, será capaz de responder de forma mais adequada às exigências do bem comum.

Na primeira parte do estudo nos debruçamos sobre a natureza dos direitos humanos, a teoria dos bens que a sustenta e um aprofundamento sobre o papel da ética da fraternidade nas deliberações sobre a concretização dos direitos humanos e o bem comum. Num segundo momento, realizamos uma análise estrutural da $D U D H$ (1948) feita à luz da teoria dos bens de John Mitchell Finnis e da pesquisa histórica de Mary Ann Glendon, para trazer, na terceira parte, um caso legislativo, como possível exemplo de aplicação do esquema interpretativo de Finnis na superação de problemas relativos à pandemia para consecução do bem comum. A ética da fraternidade, entendida como corolário da visão dos seres humanos como pessoas 'livres e iguais em dignidade e direitos', funcionará como liame entre as partes e chave de leitura para aparentes conflitos entre direitos. Ao final, ampliaremos a perspectiva estudada para uma ressignificação e fortalecimento das estruturas globais de proteção dos direitos humanos.

\section{A natureza dos direitos humanos}

Para Bobbio, quando a DUDH (1948) afirma que os seres humanos nascem livres e iguais, elabora uma ficção que ganhará vida nas mãos do legislador, um 'dever ser' almejado pelo pensamento individual, dirigido abstratamente a todos, mas concretamente a ninguém, enquanto não encontrar expressão no direito positivo como única sede da eficácia dos direitos. (BOBBIO, 2004, p.17). Essa visão, que dá visibilidade à ocorrência de colisões entre direitos, ganha relevância diante de uma situação de crise sanitária mundial, a pandemia da COVID-19. Enquanto correm debates sobre a prevalência do direito à vida sobre a liberdade de ir e vir, da aparente incompatibilidade entre o direito ao trabalho e o direito à saúde, e inúmeros outros dilemas jurídicos, muitos, na senda de Villey e MacIntyre, dão razão à ideia de que nenhum direito pode ser tido como absoluto enquanto puder ser colocado em questão por outro direito (GLENDON, 1999, p.1154) e adotam a perspectiva utilitarista para proteger direitos, com recurso ao relativismo positivista para defender qualquer política pública. 
Por outro lado, a história das Declarações de Direitos demonstra que essas buscam raízes na ideia de que certos direitos decorrem da própria natureza humana e existem desde sempre (HUNT, 2007, p.115), esse aspecto, embora notável na Declaração dos Direitos do Homem e do Cidadão (1789), já havia sido levantado na Declaração de Direitos de Virgínia (1776). (HUNT, 2007, p.121). E, ao menos desde a Idade Média, existe o empreendimento sério de extrair da natureza certa moralidade, estamos falando da concepção jusnaturalista do direito, fundada na ética cristã. Tomás de Aquino especializou ao máximo o tema ao estabelecer a relação existente entre lei eterna, lei natural, lei humana e lei divina, a partir da premissa comum de serem "proposições universais da razão prática, ordenadas para o ato" (AQUINO, ST, TL, Questão 90, art. 1), em função do bem comum. (AQUINO, ST, TL, Questão 90, Art.2). Verdade que a mentalidade que buscava conhecer o direito como expressão do justo natural acabou em parte rejeitada pelo projeto iluminista, com impacto no pensamento subsequente, mas isso não minimiza sua importância para a temática dos direitos humanos que reinaugurou o debate sobre a natureza humana e os direitos dela decorrentes, a cada crise, a cada mudança de época, como hoje ocorre. A própria Declaração Universal dos Direitos Humanos (1948) "rejeitou implicitamente a posição positivista ao estabelecer que os direitos são reconhecidos ao invés de conferidos". (GLENDON, Chap.10, p. 8).

Portanto, se podemos determinar quem é o sujeito dos direitos humanos a partir da descrição do ser humano do art. $1^{\circ}$ da DUDH (1948) como seres "livres e iguais em dignidade e direitos", isso dificilmente se faz por meio da dogmática jurídica que não tem instrumentos para reconhecer direitos, apenas para conferi-los com base em instituições. É necessário usar a linguagem da ética para desvelar o sujeito de 'direitos e deveres humanos' que só é conhecido com a menção da sequência do art. $1^{\circ}$, “devem agir uns para com os outros em espírito de fraternidade". (BARZOTTO, 2010, p. 54). Ou seja, existe uma ética que subjaz a DUDH (1948) que precisa emergir para a concretização dos direitos humanos e podemos chama-la de ética da fraternidade. Nessa senda uma teoria dos bens adequada não é aquela que coloca no indivíduo solitário a 'forma e medida' das necessidades humanas, mas na pessoa em relação que, no encontro com “o outro" é capaz de reformular as suas próprias necessidades. 


\subsection{Os bens e os direitos humanos}

O presente artigo postula que uma completa teoria dos bens como aquela elaborada por John Mitchell Finnis se mostra adequada ao escopo da $D U D H$ (1948) de fornecer um norte ético e jurídico para constitucionalismos de diversas culturas, bem como, critérios para uma tomada de decisão informada e fundamentada pelo jurista confrontado por aparentes colisões entre direitos. Mas, não obstante a completude e a adequação da teoria de Finnis, é visível a dificuldade de aplicação de sua metodologia num contexto institucional de crise da dimensão universal da ética e da política, que não mais se lança na busca dialógica da verdade e, na esteira de Hobbes, parte do pressuposto que a valoração dos bens é definida por quem exerce o poder, ou por alguma forma frágil de consenso e não por meio de uma deliberação intersubjetiva que seja capaz de dar eficácia aos princípios universais da democracia e ao mesmo tempo criar pressupostos para uma ética universal da fraternidade como condição para que seja desvelado o bem comum de uma comunidade tão complexa quanto a comunidade global. (BAGGIO, 2009, p.89). Por isso parece necessário, levando a sério a teoria dos bens de Finnis, confrontar esses bens básicos com as exigências da política atual e criar os pressupostos para um processo de deliberação fraterna, ou seja, em que 'o outro' é a condição de conhecimento de si mesmo, ao ponto de permitir ao sujeito de uma forte participação política (BAGGIO, 2009, p.91) a visão da lei natural a partir da "forma e medida" do bem comum querido para si e para outrem, identificado como bem comum da sociedade.

A premissa de Finnis é que, na superação do divisor de águas entre a concepção de ‘jus’ como justo e 'jus' como poder, perdeu-se de mira o aspecto ético do direito. Para ele o núcleo do debate sobre os direitos não está nem na vontade nem no benefício do sujeito, mas nos aspectos básicos do florescimento humano, em um elenco de bens que não somente garantem o exercício de direitos propiciando um ambiente adequado para tanto, mas algo que se manifesta sempre que um princípio básico ou exigência de razoabilidade prática, mediante uma regra, concede para qualquer pessoa ou para sua comunidade o fruto de uma obrigação positiva ou negativa imposta a um terceiro, bem como, o gozo de um bem ou de qualquer imunidade em relação à pretensão de terceiros. (FINNIS, 2011, p.205).

Mas, considerando o fato que a racionalidade prática e a ética têm sido separadas do discurso dos direitos do indivíduo, eleito como única medida de bem possível, a tarefa de distribuí-los torna-se impossível. O discurso dos direitos é levado para toda e qualquer esfera de discussão, elegendo-se como critério de 'certo' e 'errado', multiplicando as antinomias entre direitos. (GLENDON, 1991, p. 10-11). A antropologia individualista que faz uma leitura da 
DUDH (1948) cega à visão do direito como justo, consagrando o direito como poder, não só deixa de contemplar o aspecto relacional das pessoas, mas tem se mostrado insuficiente para o desenvolvimento de sociedades democraticamente sustentáveis e que sejam capazes de dialogar globalmente, com o consequente esvaziamento das instituições de governança global que foram criadas justamente para a preservação de bens universais. A visão liberal individualista que delegou às instituições internacionais a proteção dos direitos humanos sem considerar a existência de 'deveres humanos' a serem desenvolvidos não tanto com base legal, mas numa cultura, mostra-se como uma das causas da atual crise do processo de globalização ao criar a figura do 'indivíduo dependente' do Estado e das instituições internacionais e não das pessoas ‘interdependentes entre si’ e que vêm a compor uma nação, uma família global, visão de humanidade reconhecida no preâmbulo da $D U D H$ (1948).

Ao interpretar a $D U D H(1948)$, Finnis observa que o modo como se comporta o discurso dos direitos, embora facilmente compreensível como uma concessão de titularidade de benefício por meio de uma regra, pode ser melhor explicado pela existência de artigos que preveem a limitação desses mesmos direitos. (FINNIS, 2011, p. 212). Para tanto, aponta para o fato que duas formas canônicas básicas foram adotadas para caracterizar cada um dos direitos/deveres da $D U D H$ (1948), "todos têm direito a..." e "ninguém deve ser submetido a...", o que também permite apontar quais direitos são absolutos e quais podem ser eventualmente limitados. (FINNIS, 2011, p.212). Nessa linha, o art. 29 da $D U D H$ (1948) prevê limitações para 'direitos e liberdades' constantes na DUDH (1948), donde se compreende que aqueles artigos que exibem uma prescrição do tipo negativa "ninguém deve ser submetido a..." não podem em nenhuma circunstância ser objeto de limitação por qualquer espécie de jurisdição. (FINNIS, 2011, p.212). Estamos diante de direitos naturais primários, ligados aos primeiros preceitos da lei natural e direitos naturais secundários, forjados como fruto do jus gentium, espécies de bens jurídicos que não são iguais. Essa distinção é um componente interpretativo do fato que os direitos humanos são expressão histórica do direito natural (BARZOTTO, 2010, p.69), um reconhecimento dos bens necessários ao florescimento humano e portanto distingue-se seu conteúdo, que é absoluto pois cuida dos bens básicos e que não poderão ser negados à existência humana de forma absoluta (sob pena de perecimento), e sua forma de realização, que é relativa pois encarna-se num momento histórico, numa cultura, e muitas vezes são dependentes de contingências que estão fora do controle das pessoas, mas que podem e devem ser vivenciadas de forma a preservar o conteúdo absoluto dos direitos humanos e com isso o bem comum. 


\subsection{Diretos, deveres humanos e bem comum. $O$ arquétipo da fraternidade}

Para Finnis é razoável afirmar que existem direitos absolutos, enquanto outros, de acordo com a função que é dada a cada artigo da $D U D H$ (1948) na realização do bem comum, estariam sujeitos a quatro espécies de limitações:

Eles são quádruplos: (i) garantir o devido reconhecimento pelos direitos e liberdades de terceiros; (ii) atender aos justos requisitos de moralidade em uma sociedade democrática; (iii) atender aos requisitos de ordem pública em uma sociedade democrática; (iv) para atender aos justos requisitos do bem-estar geral de uma forma democrática sociedade. (FINNIS, 2011, p.213).

Embora a referência do art. 29 da $D U D H$ (1948) às limitações impostas por "bem-estar geral", "moralidade" e "ordem pública", possa padecer de certo grau de subjetividade de acordo com a cultura jurídica que interpreta, não lhes falta propósito, nem podem ser compreendidas de modo apartado do preâmbulo, até porque, no projeto inicial de Cassin, deveria integrar o fundamento da declaração. (GLENDON, Chap.10, p.13). De qualquer sorte, para Finnis, a menção aos limites específicos ao exercício dos direitos se fez necessária não somente porque cada direito traz em si uma carga de dever, mas porque

\footnotetext{
Direitos humanos somente podem ser gozados de forma segura em um determinado ambiente - um contexto ou estrutura de mútuo respeito e confiança e compreensão comum, onde se desenvolve o que é fisicamente saudável e no qual os fracos podem prosseguir sem medo dos caprichos dos fortes. (FINNIS, 2011, p.216).
}

Depreende-se então que os direitos humanos são componentes fundamentais do bem comum e estão sujeitos, ou são limitados uns pelos outros, ou por outros aspectos do bem comum que podem ser expressos como moralidade pública, ordem pública e saúde pública. (FINNIS, 2011, p. 218). Ao aplicarmos o esquema interpretativo de Finnis, com acréscimo de uma perspectiva antropológica que tem em conta tanto as fundações da $D U D H$ (1948), quanto seus precedentes históricos, têm-se então elementos qualificados para boas decisões concernentes ao aparente 'conflito' entre direitos. Essas são premissas importantes para iniciar um diálogo racional sobre concessões recíprocas entre direitos e que deveria ter condições de evoluir para uma verdadeira deliberação intersubjetiva que, para Baggio, pode ser alcançada por meio de uma ressignificação da alteridade que tem no arquétipo do Abandono de Jesus Crucificado um modelo de entrega e afirmação da existência do 'Outro' (BAGGIO, 2009, p. 124), uma predisposição de esvaziamento de si diante do semelhante como única sede em que o diálogo acontece com todo seu potencial criativo e operativo. Em que pese o aparente particularismo cristão do arquétipo eleito é importante notar que todos os seres humanos fazem a experiência da dor, da separação e da morte, e foi, fundamentalmente, a dor do holocausto e 
outras barbáries cometidas por seres humanos em relação a outros o espaço hermenêutico que possibilitou o diálogo subjacente à $D U D H$ (1948).

A visão de ser humano do preâmbulo da $D U D H$ (1948) reconhece a dignidade humana, a sua capacidade de indignação perante a barbárie, o seu anseio por liberdade:

Considerando que o desprezo e o desrespeito pelos direitos humanos resultaram em atos bárbaros que ultrajaram a consciência da Humanidade e que o advento de um mundo em que os todos gozem de liberdade de palavra, de crença e da liberdade de viverem a salvo do temor e da necessidade foi proclamado como a mais alta aspiração do ser humano comum (...). (DUDH, 1948, p. 2).

Essa sensibilidade à dor alheia, que é capaz de estender a condição de irmão a quem de fato não é, mostra-se um sucedâneo da menção feita à 'iguais em dignidade e direito', e dificilmente pode ser compreendida em abstrato, requer a experiência da co-humanidade (BARZOTTO, 2010, p. 58) para se encarnar. Por isso o recurso ao arquétipo, às histórias de pessoas que se sacrificaram na linha de frente do enfrentamento da COVID-19, daqueles que morreram abandonados por falta de cuidados médicos. Os aspectos do bem-estar humano são por um lado evidentes e passíveis de serem partilhados, por outro lado, dizem respeito a pessoas de carne e osso e devem confrontar-se necessariamente com os limites inerentes à condição humana e em especial com a morte, que parece tornar vão o gozo desses bens. (FINNIS, 2011, p. 372).

Ora, se são os conflitos entre as pessoas (não as antinomias entre direitos) a fonte dos males que "ultrajam a consciência da Humanidade", então é necessário abrir-se ao "outro", o sofredor, para conhecer a "si mesmo". É necessária a fraternidade, pressuposto de uma participação mais compreensiva das pessoas na construção do bem comum, não somente para si mesmas, mas para aqueles que virão, para dar sentido a um projeto comum de humanidade plural e ao mesmo tempo composta de livres e iguais.

\section{A Declaração Universal dos Direitos Humanos (1948). Universalidade e Interdependência}

Os autores da $D U D H$ (1948) estavam conscientes da necessidade de fazer prevalecer uma cultura sobre o direito e que a Declaração somente cumpriria seu desiderato se no mesmo passo de sua concretização fosse capaz de desenvolver uma verdadeira cultura da dignidade humana. (GLENDON, 1999, p. 13). Eles jamais pensaram que deveria existir um padrão 
uniforme a ser alcançado para fins de realização de direitos, pelo contrário, era esperado que “os direitos da Declaração fossem inculturados em de várias maneiras, e que com o tempo o corpus de direitos humanos seria enriquecido por essas experiências variadas". (GLENDON, 1999, p. 7). A $D U D H$ (1948) exprime em seu preâmbulo uma sorte de consenso metafísico que emergiu dos primeiros debates da Comissão, com a ideia de que "todo ser humano tem o direito de ser tratado como outro ser humano" e o conceito de "solidariedade e fraternidade entre os seres humanos". (GLENDON, Chap. 4, p. 37-38). Quando lida como um todo, a DUDH (1948) apresenta-se um empreendimento construído sob o princípio da dignidade da pessoa humana, vista como parte da família humana. Trata-se de um documento de interdependência entre povos, culturas e nações (GLENDON, Chap. 10, p. 3), interdependência essa que é sentida de fortemente após a pandemia da COVID-19, chamando em causa a atualidade da Declaração.

Glendon apresenta a $D U D H$ (1948) como um edifício que tem no preâmbulo seu átrio de ingresso, os dois primeiros artigos representam o fundamento que sustenta quatro colunas e um frontão que estabelece limites para o exercício dos direitos e assunção de obrigações perante a comunidade, bem como, uma abertura ao futuro, à novas perspectivas quanto ao estabelecimento de direitos. (GLENDON, 2004, Chap. 10, p. 41). Essa visão é útil para a elaboração de um projeto de bem comum da humanidade, que assumiu para si a tarefa de reconhecer a lei natural, o justo, como objeto dos direitos humanos, de modo que não ficasse ao arbítrio dos poderosos a escolha dos bens que seriam concedidos aos mais humildes.

O primeiro esboço da $D U D H$ (1948) foi resultado de um meticuloso trabalho de pesquisa sobre a filosofia de diversas culturas e diversas tradições constitucionais, o que garantiu a universalidade da proposta, condensando "em um documento quase duzentos anos de esforços para articular os mais básicos valores em termos de direitos". (GLENDON, 2004, Chap. 4, p. 13). Nos bens básicos na tríade tomista dos primeiros princípios da lei natural, vida, comunidade e verdade, e nos preceitos que estão à base dos direitos humanos, tais como a dignidade humana e fraternidade temos o princípio de justificação dos direitos humanos (BARZOTTO, 2010, p. 76) e que pode ser compreendido universalmente, pré-condição axiológica para um diálogo sobre os bens mais caros à humanidade, expressos em termos de direitos civis, políticos, sociais e econômicos.

Para Cassin, que foi responsável pela estruturação do texto, a Declaração deveria embasar direitos universais "no grande princípio fundamental da unidade de todas as raças da espécie humana", daí a descrição primitiva de humanidade do art. $1^{\mathrm{o}}$ "todos os homens, por serem membros de uma família, são livres e possuem igual dignidade e direitos, e devem 
considerar-se um ao outro como irmãos". Depois esse artigo acabou sendo revisado para acrescentar o dom da razão como constitutivo da espécie humana e, sob a moção de Chang, representante da China, todos concordaram em acrescentar uma noção oriental intraduzível, 'ren', que poderia expressar 'uma pessoa em relação a outra', ou compaixão, na terminologia de Rousseau. Ao final a palavra escolhida foi "consciência", termo que não exprime o que Chang estava propondo e, somente num esforço interpretativo poderíamos dizer "consciência sobre o outro", ou empatia. (GLENDON, Chap.4, p. 39-41). A presença de conceitos como 'consciência', 'dignidade' e 'fraternidade' em diversas culturas foi importante para a universalização de uma visão de humanidade por meio de uma Declaração de direitos. Portanto, a $D U D H$ (1948) não é neutra como tantos pretendem em relação a uma determinada antropologia e os bens lá elencados podem ser tidos como comprometidos com a construção de um determinado tipo de humanidade, comunidade democrática que se relaciona como uma família desde a menor célula até a comunidade internacional.

\subsection{Os bens protegidos pela Declaração Universal dos Direitos Humanos (1948)}

Ao tomarmos a tríade tomista dos bens, vida, comunidade e verdade que, como dito, são fruto da relação estabelecida pela razão entre lei natural e lei humana, para ir aos detalhes, chegamos aos bens elencados por Finnis como necessários ao florescimento humano. Esses bens, não sem razão, exibem similitude com os direitos reconhecidos pela $D U D H$ (1948).

O primeiro bem a ser considerado como básico é a vida, que contempla desde a corporeidade e o reconhecimento da dignidade da vida humana à procriação e todas as formas de preservação da vida. (FINNIS, 2011, p. 87). Na DUDH (1948) aparece uma menção explícita à vida no art. $3^{\circ}$, bem como, na sua quarta coluna, entre as referências feitas pelo art. 25 ao direito à saúde, a proteção à maternidade e à infância. Considerando a generalidade da Declaração outros temas relativos à saúde pública deixaram de ser abordados em respeito às soberanias nacionais. De qualquer sorte e, tendo presente que o direito à vida está no cerne do debate relativo ao enfrentamento da pandemia, é importante apontar para a falha ética de incorrer em preferências arbitrárias entre valores, citada por Finnis entre os requisitos da razoabilidade prática. (FINNIS, 2011, p. 105). Além disso, é importante fazer preceder o debate relativo ao enfrentamento da pandemia em tudo que foi dito anteriormente acerca do fundamento dos direitos humanos e tudo o que se dirá na sequência sobre a busca da verdade. 
Com lastro em Aristóteles e Aquino, o segundo bem é o conhecimento. Esse é visto de forma privilegiada em relação aos demais por ser um indicativo natural da finalidade da vida humana, exprime não tanto o conhecimento instrumental, mas o anseio e a busca por conhecer a verdade por si mesma, de evitar erro e ignorância, bem como, obter julgamentos corretos. (FINNIS, 2011, p. 59). O direito de gozar desse bem incomensurável encontra eco tanto no direito de reconhecimento da personalidade da pessoa e a um procedimento criminal justo, da primeira coluna, quanto no direito à liberdade de pensamento e imprensa da terceira coluna, como no direito à educação da quarta coluna da $D U D H$ (1948). O conhecimento não é um bem para ser retido para si mesmo, mas que tem o condão de ser comunicado com outros, e com isso o potencial de criar comprometimento com projetos comuns (FINNIS, 2011, p.64), de tal sorte que a realização de outros bens sequer é possível sem gozo desse bem básico.

O terceiro e quarto bens contemplados no esquema de Finnis representam o aspecto lúdico da vida humana, ou seja, o jogo e a experiência estética, que aparecem no art. 27 da $D U D H(1948)$ no que se refere ao direito ao gozo de produção cultural e artística. A importância do lúdico é vista de forma aumentada enquanto as pessoas vivem em isolamento social, isso porque tece liame entre conhecimento e sociabilidade, faz o ser humano participar da beleza da natureza transformando-a em obras inéditas. (LUBICH, 2001, p. 348).

A sociabilidade ou amizade é o quinto bem a ser considerado, e engloba as formas de associação desde a família, passando pelo trabalho, até a possibilidade de participação na política e nas decisões de uma sociedade democrática. É possível vislumbrar esse bem como reconhecido na proteção dada à família da segunda coluna da $D U D H$ (1948), liberdade de associação e participação política, da terceira coluna e direito ao trabalho, da quarta coluna.

\section{A racionalidade e a moralidade exigidas nas decisões concernentes à pandemia}

Considerando a antropologia que sustenta a $D U D H$ (1948), uma determinada teoria dos bens e a utilidade do mencionado esquema interpretativo de Finnis de quatro graus de limitação de direitos, em confronto com a urgência de limitações de direitos exigidas pela pandemia no Brasil, percebe-se que foi exigida dos Estados e Municípios a aplicação do primeiro grau de limitação de direitos, ou seja, aquele que faz apelo ao "devido reconhecimento pelos direitos e liberdades de terceiros", ou seja, não era o caso de invocar as limitações exigidas com o fim 
de preservar a ordem pública, nem a moralidade pública, nem o bem estar geral de uma sociedade democrática, mas de garantir que o exercício de direitos tão importantes quanto direito de reunião, culto, locomoção e trabalho por muitos, não viessem impedir que outros gozassem do direito à vida e saúde.

Por exemplo, o estado de calamidade pública declarado pelo Dec. 20.534/2020 do Município de Porto Alegre e pelo Dec. 55.128/2020 do Estado do Rio Grande do Sul, não se enquadram nas previsões constitucionais de limitação de direitos dos arts. 136 e seguintes da $\mathrm{CF}$, que demandariam aplicação dos três últimos graus de limitação de direitos, mas são fruto da competência concorrente ou suplementar concedida a Estados e Municípios pelos arts. 24, XII e 30, II da Constituição Federal. No Município de Porto Alegre por força do referido Decreto Municipal o comércio de bens e serviços não essenciais fechou suas portas e ordenado o isolamento domiciliar de pessoas de mais de 60 anos (art.43), mas sem imposição de alguma penalidade. A população em geral foi orientada publicamente a isolar-se, mas tratou-se de um isolamento voluntário, com efeitos positivos sobre a curva de avanço da COVID-19, permitindo que o sistema de saúde se preparasse adequadamente para enfrentá-la.

Não se trata então de dar prevalência a um ou outro direito, como se estivessem colocados sobre uma balança consequencialista (FINNIS, 2011, p. 119) mas de, com base em informações, criar as condições para que as decisões tomadas em um gabinete de crise tenham razoabilidade prática e, mesmo com o sacrifício de algum bens condicionais, não atinjam diretamente bens incondicionais, e que ao menos um valor básico seja preservado em cada decisão (FINNIS, 2011, p. 120). A mera fixação de objetivos consequencialistas, como 'proveito líquido' de uma determinada medida, nada mais faz que instrumentalizar bens ligados à personalidade com esses, os próprios seres humanos:

Quando alguém está decidindo o que fazer, não pode razoavelmente fechar os olhos para a estrutura causal do projeto; (...). Não poderá engajar-se senão diretamente com um bem básico, como a vida humana. (FINNIS, 2011, p. 121).

Ainda, do ponto de vista ético, para que uma decisão pudesse ser considerada razoável, a pessoa deveria estar suficientemente desapegada de seus impulsos e de um projeto específico, de modo que todos os valores básicos sejam considerados com abertura criativa, o que permitiria que eventuais danos laterais às pessoas fossem minimizados e danos definitivos evitados. (FINNIS, 2011, p. 123). Ou seja, é importante ter em mente que danos à saúde das pessoas têm grande risco de tornarem-se definitivos, o que exige que responsabilidades comuns sejam assumidas no enfrentamento da pandemia, inclusive para além das prescrições legais, como ocorreu quando muitos brasileiros isolaram-se volutariamente de modo a evitar a 
propagação da COVID-19. Mesmo na ausência de respostas legais, mesmo na inação dos entes governamentais, sempre será possível ao ser humano extrair de sua natureza uma resposta da lei natural para uma crise comunitária.

Estamos diante de uma faceta da aplicação do princípio da fraternidade que, além de garantir a sobrevida da liberdade e igualdade, "responsabiliza cada indivíduo pelo outro e, consequentemente, pelo bem da comunidade, e promove a busca de soluções para a aplicação dos direitos humanos que não passam necessariamente pela autoridade pública". (AQUINI, 2008, p.138). E, se os direitos que têm carga negativa, "ninguém deve ser...”, que são alguns dos direitos de liberdade das três primeiras colunas da declaração, não podem ser absolutamente desrespeitados, mas é possível haver concessões recíprocas entre direitos positivos de liberdade, de fórmula "todos tem direito de...", e direitos de igualdade que são veiculados na quarta coluna da $D U D H$ (1948), essa mediação ocorre pela aplicação do art. 29 da $D U H D$ (1948) que é um sucedâneo do dever de fraternidade do art. $1^{\circ}$ do mesmo diploma e síntese de compreensão dos direitos humanos como uma responsabilidade assumida em comunidade e de deveres éticos que se concretizam no cotidiano de pessoas de carne e osso.

\section{Direitos e Deveres. Uma ética universalizável da fraternidade}

Há quem lamente o fato que a Declaração contentou-se com a referência genérica e não trouxe menção específica a deveres sociais e comunitários. Durante os debates para a elaboração da $D U D H$ (1948), em outubro de 1948, houve intensa discussão sobre a possibilidade de confrontar o projeto preliminar de Humphrey com a Declaração Americana dos Direitos e Deveres do Homem da OEA (1948), que contém em seu bojo um rol de 'deveres humanos'. Mas a ideia acabou deixada de lado ante a constatação de que esse texto, que era nutrido por uma filosofia ocidental, não poderia ser seguido por outras culturas. (GLENDON, Chap. 8, p. 43-44). Essa discussão precedeu um aumento da preocupação acerca da falta de menção à específicas responsabilidades comunitárias no texto da $D U D H$ (1948). Para Chang, delegado da China, era de extrema importância a menção a deveres pois o objetivo das Nações Unidas seria aquele de promover uma melhora na estatura moral da humanidade, mas prevaleceu a ideia de Cassin de que todo o texto cobriria a ideia de deveres (GLENDON, Chap.8 p. 44), ou seja, Cassin fazia presumir a existência de direitos, a correlatividade dos deveres e isso não somente como apelo ao art. 29, mas à essência do próprio direito como justo natural. 
Finnis lembra que para certas tribos da África direito e dever seriam termos abrangidos por uma mesma palavra (FINNIS, 2011, p. 209) e se o comunitarismo africano e suas diferentes visões de mundo não foram suficientemente consideradas na construção cultural da $D U D H$ (1948) ao menos podemos dizer que essa ideia é plenamente compreensível para o povo africano que possui em si um grau intenso de comunitarismo onde as relações familiares são experimentadas para além do vínculo de parentesco. (ZANZUCHI, 2002, p.65).

Para Finnis, a comunidade, em seu aspecto básico se dá pela eleição de objetivos e projetos comuns e a relação entre os membros da comunidade, em seu aspecto mais significativo, é a amizade. Ora, a amizade é uma forma de relacionamento qualificada pelo afeto a tal ponto que o bem estar do amigo é o seu e essa experiência é fundadora de sentido para tudo aquilo que é feito com sacrifício pessoal visando o bem de uma comunidade (FINNIS, 2011, p.372), mas isso pode não ser visto como suficiente para justificar o sacrifício pessoal feito pela comunidade global, por alguém cujo bem não é visível como ocorre quando toda humanidade está exposta ao contágio, momento em que a contingência tornou visível a existência de um bem comum através da emergência de um mal comum, um momento da humanidade que desvela em instantes a objetividade do bem humano, escondendo a subjetividade tão intensamente experimentada durante os últimos desenvolvimentos fragmentários resultantes da globalização.

Mesmo que admitamos que esses anseios nacionalistas e fragmentários estejam ainda em pleno desenvolvimento, percebe-se que a pandemia, ao mesmo tempo que descortina a incompletude inerente ao projeto dos direitos humanos, oferece um novo espaço hermenêutico para que eles sejam concretizados à luz de uma racionalidade que tem como premissa o reconhecimento do outro como alguém a quem chamar de 'tu', uma pessoa que, por ser um semelhante, é um ‘irmão' pelo qual é possível ter um amor consciente, ou 'ren', como diria Chang, porque é através do 'irmão' que a pessoa se identifica. Assim como Tomás de Aquino propõe uma secularização da igualdade, pressionando pela ruptura dos limites feudais impostos por sectarismos aristocráticos, para assim forjar uma ética universalista da fraternidade laica (BARZOTTO, 2010, p.25), os tempos de hoje urgem pela superação de bairrismos e intransigências culturais que até hoje impedem a realização dos direitos humanos, quando violações são abrigadas pelo manto por vezes nefasto de soberanias que tolhem o acesso das pessoas à verdade, como demonstram fatos aterradores da história recente. $\mathrm{O}$ fato que a soberania pode ser obstáculo à realização dos direitos humanos demanda a utilização de instrumentos de diálogo multilateral ou, uma 'aprendizagem' multilateral e complementar, em 
uma alteração livre da expressão de Habermas (2006, p. 21). É necessário que, os princípios da justiça penetrem previamente a trama complexa de diversas concepções culturais (HABERMAS, 2006, p.13) e, partindo de premissas comuns inerentes à dignidade humana, admitamos os limites das próprias culturas para ampliar a capacidade humana de compreenderse em relação ao outro e criar as condições para uma cultura da fraternidade.

\section{Conclusão}

A $D U D H$ (1948) representa um empreendimento em si incompleto, que contém muito do que é necessário para a compreensão da natureza humana, bem como, uma ética subjacente que permite que os direitos humanos sejam lidos como instrumento da realização do bem comum mediante o esforço da fraternidade, da abertura ao outro e às gerações futuras. Não é possível haurir frutos dos mecanismos internacionais de proteção aos direitos humanos sem a adoção generalizada de uma ética universalista da fraternidade. (BARZOTTO, 2010, p.60). Essa ética, que em parte é experimentada dentro de comunidades de vizinhança, não é imediatamente universalizável nem pode ser implementada por imposição legal, mas pode ser estimulada, aprendida por meio de exemplos, histórias e testemunhos.

Se a fraternidade experimentada em uma comunidade de vizinhança ensina que "é devedora em termos éticos em relação a toda pessoa humana sob pena de mutilar sua própria humanidade". (BARZOTTO, 2010, p.57) e para realizar e viver a experiência da família humana é que muitos direitos são tutelados pela $D U D H$ (1948), então não é equivocado esperar na universalização da ética da fraternidade. Para Agnes Bernhard:

Entendemos a realização da fraternidade como o interesse comum da humanidade. A
interdependência dos homens em todos os lugares e em todos os momentos e em seu
espaço de vida constitui, do ponto de vista da fraternidade, uma unidade que é um pré-
requisito para uma responsabilidade comum. (BERNHARD, 2005, p. 53).

Assim como para Aristóteles todo e qualquer bem é negligenciado pelo valor da amizade, podemos dizer com maior propriedade que todo e qualquer bem pode ser colocado em segundo plano diante do desejo de viver 'em família' ou num ambiente 'fraternal' que, partindo da compaixão por quem sofre, tem o condão de alarga-se à humanidade. Nas palavras de Chiara Lubich, "é a fraternidade que nos realiza como cidadãos" e, se a cidade é o lugar onde a fraternidade é vivida concretamente, é também a sede onde amadurece aquilo que a pessoa tem em si de universal, a sua própria humanidade. (LUBICH, 2001, p.307) 


\section{REFERÊNCIAS}

AQUINI, Marco in BAGGIO, Antonio Maria. org. Fraternidade e Direitos Humanos. O princípio esquecido. Cidade Nova, 2008, p.127-151

AQUINO, Tomás de. Tratado da Lei in Suma Teológica.

BERNHARD, Agnes. in CASO, Gianni. org. Elementi del Concetto di Fraternità e Diritto Costituzionale, Atti del Convegno Castelgandolfo 18-20 novembre 2005. Relazionalità nel diritto: quale spazio per la fraternità? 2006.

BAGGIO, Antonio Maria. A inteligência fraterna. in O Princípio Esquecido, vol.II, São Paulo. Ed. Cidade Nova. P. 85-129. 2009.

BARZOTTO, Luis Fernando. Filosofia do Direito: os conceitos fundamentais e a tradição jusnaturalista. Porto Alegre: Livraria do Advogado. 2010.

BOBBIO, Norberto. A era dos direitos. Rio de Janeiro. Elsevier. 2004

FINNIS, John Mitchell. Natural Law and Natural Rights. New York. Ed. Oxford University Press. 2nd Edition. 2011.

GLENDON, Mary Ann. A world made new. Eleanor Roosevelt and the Universal Declaration of Human Rights. New York: Random House. 2001.

GLENDON, Mary Ann. Rights Talk. The impoverishment of the political discourse. New York. The Free Press. 1991.

GLENDON, Mary Ann. Knowing the Universal Declaration of Human Rights. Notre Dame Law Review, Volume 73 issue 5.1999.

HARBEMAS, Jurgen. RATZINGER. Joseph. Sobre la fundamentación del Estado Democrático a partir de las fuentes de la razón práctica. Dialectica de la Secularizacion. Madrid. Ediciones Encuentro. 2006.

HUNT, Lynn. Inventing Human Rights. New York. W. W. Norton \& Company. 2007

LUBICH, Chiara. La Dottrina Spirituale. Roma. Mondadori. 2001

ZANZUCHI, Michelle. Fontem. Un nuovo popolo. Roma. Città Nuova. 2002 